\title{
Influence of Cement Type and Water-to-Cement Ratio on the Formation of Thaumasite
}

\author{
Ailian Zhang and Linchun Zhang \\ Department of Civil Engineering, Sichuan College of Architectural Technology, Deyang 618000, China
}

Correspondence should be addressed to Ailian Zhang; zhangailian1980@163.com

Received 11 April 2017; Accepted 7 June 2017; Published 9 July 2017

Academic Editor: Xiao-Yong Wang

Copyright (C) 2017 Ailian Zhang and Linchun Zhang. This is an open access article distributed under the Creative Commons Attribution License, which permits unrestricted use, distribution, and reproduction in any medium, provided the original work is properly cited.

Cement mortar prisms were prepared with three different cement types and different water-to-cement ratios plus $30 \%$ mass of limestone filler. After 28 days of curing in water at room temperature, these samples were submerged in $2 \%$ magnesium sulfate solution at $5^{\circ} \mathrm{C}$ and the visual appearance and strength development for every mortar were measured at intervals up to 1 year. Samples selected from the surface of prisms after 1-year immersion were examined by X-ray diffraction (XRD) and Fourier transform infrared (FTIR) spectroscopy. The results show that mortars with sulfate resisting Portland cement (SRC) or sulphoaluminate cement (SAC) underwent weaker degradation due to the thaumasite form of sulfate attack than mortars with ordinary Portland cement (OPC). A lower water-to-cement ratio leads to better resistance to the thaumasite form of sulfate attack of the cement mortar. A great deal of thaumasite or thaumasite-containing materials formed in the OPC mortar, and a trace of thaumasite can also be detected in SRC and SAC mortars. Therefore, the thaumasite form of sulfate attack can be alleviated but cannot be avoided by the use of SAC or SRC.

\section{Introduction}

In recent years, it has become a common practice to incorporate fine limestone powder as an additional constituent in the cement production [1]. A high volume of limestone filler is also used frequently to increase the content of fine particles and optimize the particle packing in self-compacting concrete (SCC) mixes [2]. The use of limestone in cement or concrete seems to have many benefits, such as reducing water demand, improving strength development, and being economical $[3,4]$. It was also reported that the addition of a finely ground limestone filler has a positive effect on the behavior of mortars exposed to magnesium sulfate solution due to the improved compactness [5]. However, it has been widely reported that cement and concrete containing limestone are subject to a special type of sulfate attack, attributed to the formation of thaumasite $\left(\mathrm{CaSiO}_{3} \cdot \mathrm{CaCO}_{3} \cdot \mathrm{CaSO}_{4} \cdot 15 \mathrm{H}_{2} \mathrm{O}\right)$ at low temperatures (lower than $15^{\circ} \mathrm{C}$ ) $[6,7]$. Since the formation of thaumasite involves the reaction of C-S-H in the cement paste with carbonate and sulfate ions [8], it results in severer and quicker decomposition of cement and concrete than conventional sulfate attack attributed to ettringite $\left(3 \mathrm{CaO} \cdot \mathrm{Al}_{2} \mathrm{O}_{3} \cdot 3 \mathrm{CaSO}_{4} \cdot 31 \mathrm{H}_{2} \mathrm{O}\right)$. And the use of sulfate resisting Portland cement with low $\mathrm{C}_{3} \mathrm{~A}$ content becomes ineffective to preserve cementitious materials against the thaumasite form of sulfate attack [9]. Sulphoaluminate cement, being completely different from Portland cement in mineral composition, has been used increasingly in concrete structures constructed in winter, especially in hydraulic engineering and structure remedial engineering [10-12], and there are few published studies concerning the thaumasite form of sulfate attack of this cement. Therefore, this paper presents experimental results related to the effect of cement type and water-to-cement ratio on the resistance to thaumasite sulfate attack of mortars containing a limestone filler.

\section{Experimental}

Three types of cement were used: ordinary Portland cement (OPC), sulfate resisting Portland cement (SRC), and sulphoaluminate cement (SAC). All of them have the same strength grade of 42.5 according to Chinese standards. The chemical compositions of these cement types are shown in Table 1. The ground limestone filler has a specific surface area of 
TABLE 1: Chemical compositions of cement (wt.\%).

\begin{tabular}{lcccccccc}
\hline Number & $\mathrm{CaO}$ & $\mathrm{SiO}_{2}$ & $\mathrm{Al}_{2} \mathrm{O}_{3}$ & $\mathrm{Fe}_{2} \mathrm{O}_{3}$ & $\mathrm{MgO}$ & $\mathrm{SO}_{3}$ & $\mathrm{R}_{2} \mathrm{O}$ & \multicolumn{1}{c}{$\mathrm{IL}$} \\
\hline OPC & 61.27 & 21.04 & 6.94 & 2.36 & 1.32 & 1.94 & 0.97 & 3.76 \\
SRC & 63.52 & 22.75 & 4.12 & 4.37 & 2.19 & 2.01 & 0.68 & 0.33 \\
SAC & 41.53 & 8.10 & 30.32 & 3.41 & 3.60 & 11.93 & - & 0.65 \\
\hline
\end{tabular}

TABLE 2: Mixing proportions of mortar.

\begin{tabular}{|c|c|c|c|c|c|c|}
\hline Number & OPC & SRC & SAC & Sand & Limestone & Water \\
\hline OPC (0.6) & 1.0 & 0 & 0 & 2.2 & 0.3 & 0.6 \\
\hline SRC & 0 & 1.0 & 0 & 2.2 & 0.3 & 0.6 \\
\hline SAC & 0 & 0 & 1.0 & 2.2 & 0.3 & 0.6 \\
\hline SAC50 & 0.5 & 0 & 0.5 & 2.2 & 0.3 & 0.6 \\
\hline 0.5 & 1.0 & 0 & 0 & 2.2 & 0.3 & 0.5 \\
\hline 0.4 & 1.0 & 0 & 0 & 2.2 & 0.3 & 0.4 \\
\hline
\end{tabular}

$420 \mathrm{~m}^{2} / \mathrm{kg}$ (Blaine). The fine aggregate was quartz sand with a fineness modulus of 2.5 , an apparent density of $2.65 \mathrm{~g} / \mathrm{cm}^{3}$, and a bulk density of $1.60 \mathrm{~g} / \mathrm{cm}^{3}$. The sulfate solutions were prepared by synthetic $\mathrm{MgSO}_{4}$.

Mortar prisms $(40 \times 40 \times 160 \mathrm{~mm})$ were cast according to the mixture proportions presented in Table 2. The prepared specimens were kept in a moist cabinet and cured for 24 hours at room temperature. Then, all the specimens were removed from the mould and cured in water. After 27 days of curing, all the specimens were immersed into $2 \%$-byweight $\mathrm{MgSO}_{4}$ solution at $5^{\circ} \mathrm{C}$. After every 2 months, the sulfate solution was replaced keeping the volume ratio of $\mathrm{MgSO}_{4}$ solution to prepared specimens at 2:1. For every mixture specimen, the visual appearance and strength were measured after immersion treatment in $\mathrm{MgSO}_{4}$ solution at regular intervals up to 1 year. Samples were selected from the surface of prisms after strength testing at different immersion ages. X-ray diffraction (XRD) and Fourier transform infrared (FTIR) spectroscopy were used to analyze these samples and distinguish the degraded products of cement mortar after sulfate exposure at lower temperature.

$\mathrm{X}$-ray diffraction (XRD) analysis was conducted using a diffractometer (D/MAX-IIIA, Rigaku, Japan) with $\mathrm{Cu}$ $\mathrm{K} \alpha$ radiation to identify the phase formed before and after immersion into the sulfate solution. The diffraction data was collected for each specimen under the following conditions: $2 \theta$ range of 5 to $60^{\circ}$, a count time of $0.6 \mathrm{~s}$ per step, and sampling width of $0.02^{\circ}$. Fourier transform infrared (FTIR) spectroscopy was carried out to identify the chemical and structural changes using a Nicolet 60 SXB FTIR Spectrophotometer. A mixture of synthesized powder and spectroscopic grade $\mathrm{KBr}$ was ground and then pressed at 2000 psi for $5 \mathrm{~min}$ to obtain a pellet, and the corresponding wavenumber ranged from $400 \mathrm{~cm}^{-1}$ to $4000 \mathrm{~cm}^{-1}$.

\section{Results and Discussion}

3.1. Visual Appearance. Visual appearances of the tested mortar specimens were detected for every mixture monthly.
It can be found that there is a little of a white precipitate on the surface of the mortar specimens after the initial 27-day curing in water for all the mortars except for SAC mixture, being mainly attributed to the $\mathrm{CH}$ leaching out from the mortar and a little of carbonate in water. During the first several months of immersion in the sulfate solution, such white mass exudation continued and it seemed to have no negative influence on the mortar mechanical performance. There were firstly some signs of deterioration on the surfaces and edges of the samples after 4 months for the OPC mortar but a longer time of 6 months for other mortars.

Visual appearances of the tested specimens were detected for every mixture after 1-year exposure to sulfate solution at $5^{\circ} \mathrm{C}$. The results for typical mixtures are presented in Figure 1. It can be found that there are obvious signs of deterioration on the specimen surfaces for every specimen. And a white soft substance was formed on the container's bottom resulting from the spalling specimen surfaces. From the visual appearance, it was found that the OPC mortar exhibited the worst damage, sulfate resisting Portland cement (SRC) mortar showed a limited improvement, and the mortars containing sulphoaluminate cement (SAC and SAC50) underwent much weaker damage. Therefore, both SRC and SAC showed improved resistance to the thaumasite form of sulfate attack, and the latter is better. With the decreasing of the water-to-cement ratio from 0.6 to 0.4 , the mortar presented less appearance damage.

3.2. Strength Development. Figure 2 presents the strength development of mortars with different types of cement immersed in sulfate solution. No significant strength reduction occurred on the OPC mortar during the beginning of the 3 months, and a little strength increase happened on other mortars. With the continued exposure to sulfate attack, the strength of every mortar began to decrease and the strength loss increased evidently with the increasing of immersion time. After 1-year immersion in sulfate solution, OPC, SRC, SAC, and SAC50 mortars showed 72.8\%, 53.6\%, 35.6\%, and $25.6 \%$ compressive strength loss and $45.6 \%, 35.1 \%, 25.0 \%$, 


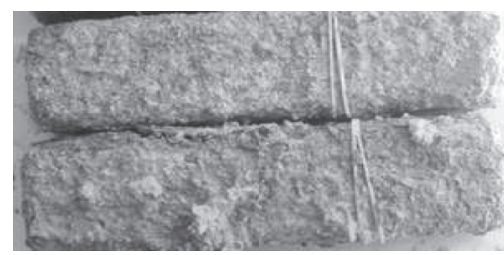

(a)



(d)

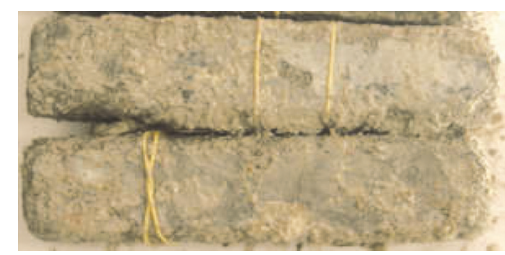

(b)

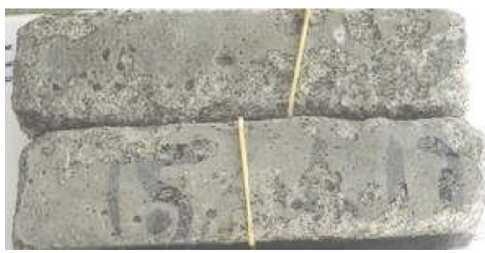

(e)

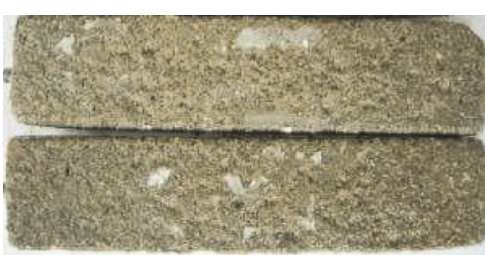

(c)

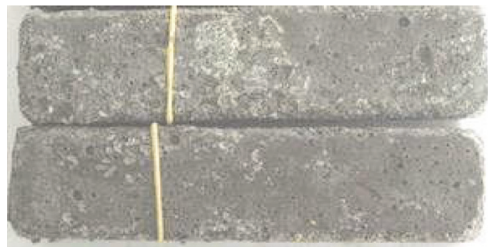

(f)

FIGURE 1: Visual appearance of mortars after 1-year exposure to sulfate: (a) OPC (0.6), (b) SRC, (c) SAC, (d) SAC50, (e) 0.5, and (f) 0.4.



(a)

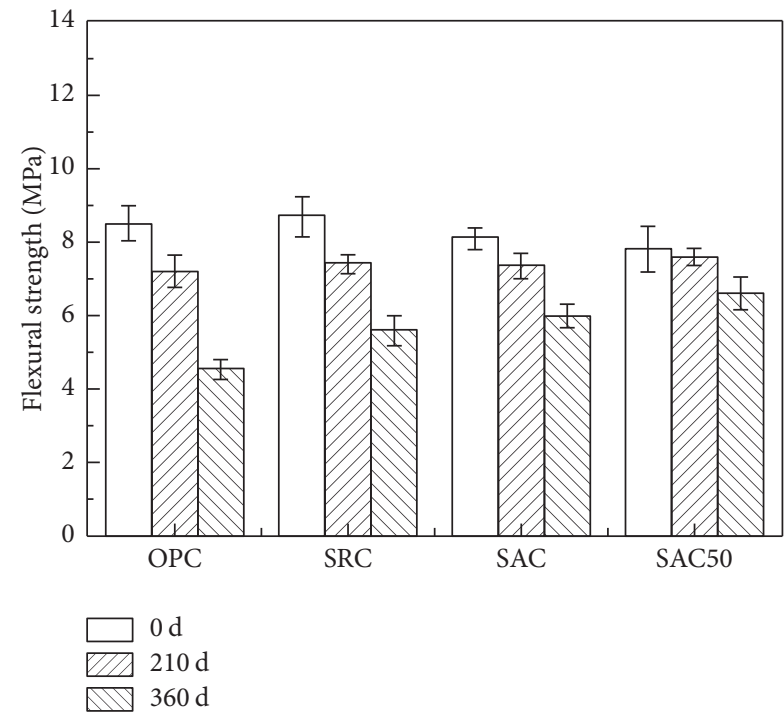

(b)

FIGURE 2: Strength development of mortars with different types of cement with immersion time: (a) compressive strength, (b) flexural strength.

and $15.6 \%$ flexural strength loss, respectively. Though sulfate resisting Portland cement mortar shows a less strength loss than OPC mortar, it does not behave as good as expected for the traditional sulfate attack. Sulphoaluminate cement shows much better resistance to sulfate attack at lower temperature than OPC mortar. These results agree with those of the above visual inspection.

Figure 3 presents the strength development of mortars with different water-to-cement ratios immersed in a sulfate solution. After the first 3 months of immersion, just a very little decrease in compressive strength was found for the control mortar with water-to-cement ratio of 0.6 , and the other two mortars with lower water-to-cement ratios of 0.5 and 0.4 showed an obvious strength increase. With the continued exposure to sulfate attack, the strength of every mortar began to decrease and the strength loss increased with the increasing of immersion time. After 1-year immersion in sulfate solution, mortars with water-to-cement ratios of 0.6 , 0.5 , and 0.4 showed $72.8 \%, 26.9 \%$, and $15.0 \%$ compressive strength loss and $45.6 \%, 9.8 \%$, and $3.1 \%$ flexural strength loss, respectively. This weaker damage is mostly attributed to the improved porosity and impermeability of mortar with a lower water-to-cement ratio. Therefore, a lower water-tocement ratio is very effective for improving the resistance to the thaumasite form of sulfate attack.

3.3. Mineralogy. The samples were selected from mortars after the initial 27-day curing in water and XRD patterns of them are shown in Figure 4. For all the samples, strong peaks corresponding to quartz $\left(\mathrm{SiO}_{2}\right)$ from the sand and calcite 


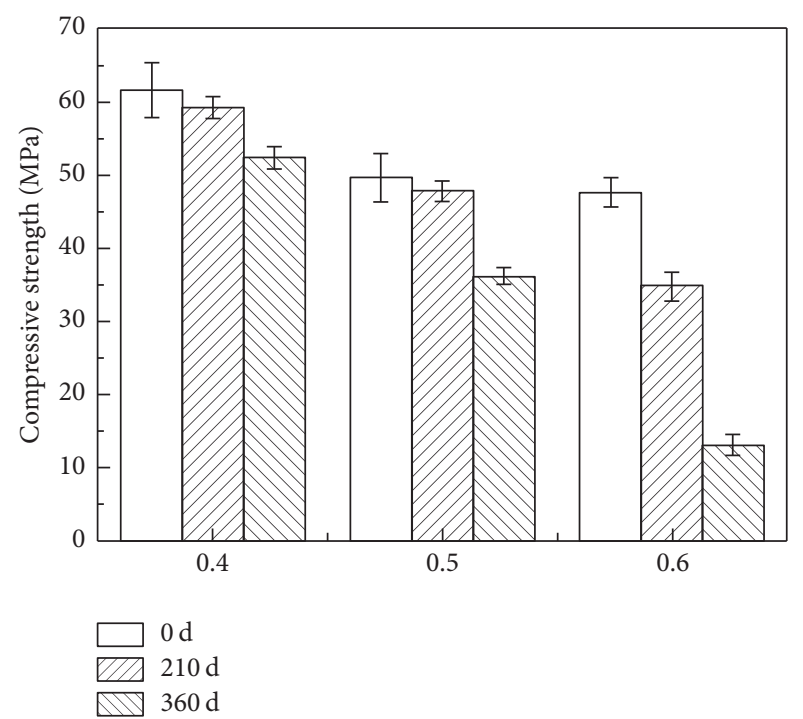

(a)

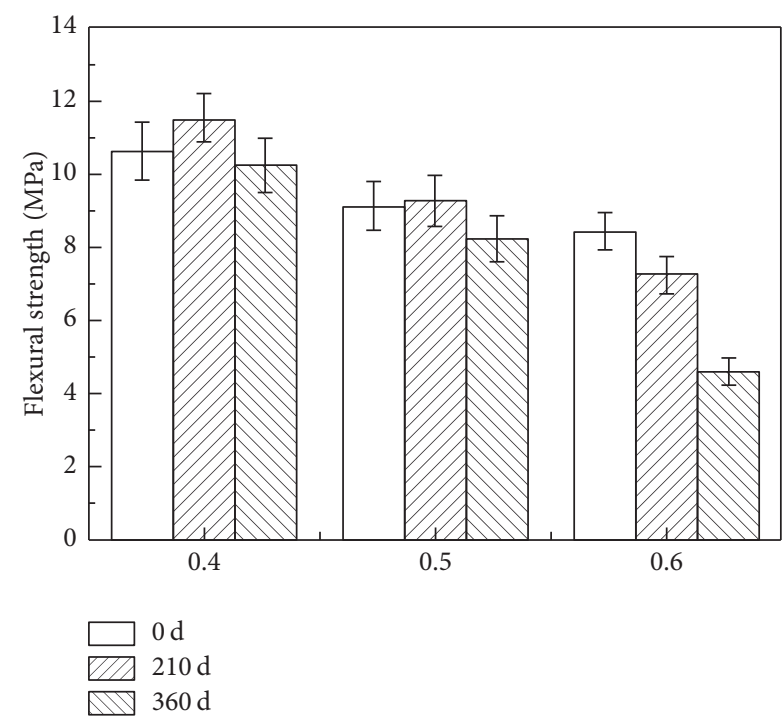

(b)

FIGURE 3: Strength development of mortars with different water-to-cement ratios with immersion time: (a) compressive strength, (b) flexural strength.
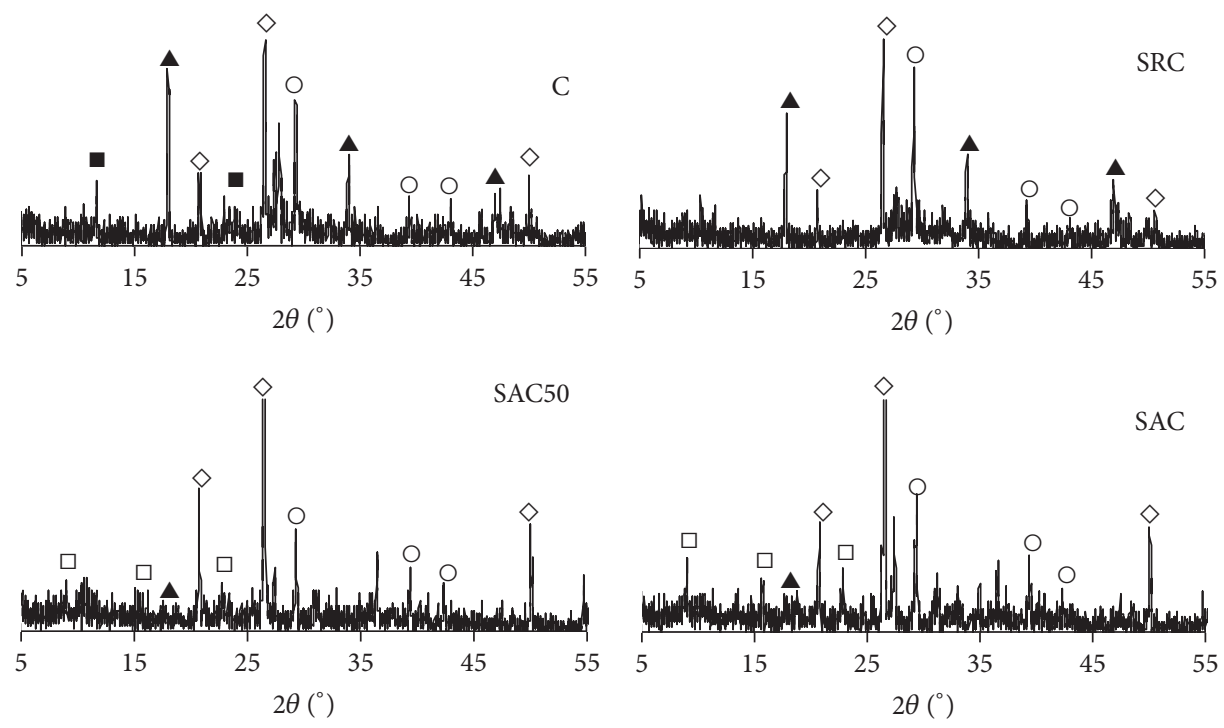

FIGURE 4: XRD patterns of mortars before immersion into sulfate solution. $\diamond$ : quartz; $\bigcirc$ : calcite; $\mathbf{\Delta}$ : portlandite; $\mathbf{\square}$ : monocarboaluminate; $\square$ : ettringite.

$\left(\mathrm{CaCO}_{3}\right)$ from the limestone filler were found. As expected, a mass of portlandite $\left(\mathrm{Ca}(\mathrm{OH})_{2}\right)$ formed in OPC and SRC mortars. Monocarboaluminate $\left(3 \mathrm{CaO} \cdot \mathrm{Al}_{2} \mathrm{O}_{3} \cdot \mathrm{CaCO}_{3} \cdot 11 \mathrm{H}_{2} \mathrm{O}\right)$ formed as one of the hydration products of $\mathrm{C}_{3} \mathrm{~A}$ from OPC and limestone filler. When the mortar is immersed into the sulfate solution, sulfate ions penetrate into the mortar and react with portlandite, monosulfoaluminate, $\mathrm{CSH}$ gel to form ettringite, gypsum, and thaumasite [13, 14]. The formation of these products leads to the swelling, cracking, and finally decomposition of the OPC mortar. No detectable monocarboaluminate was found in the sulfate resisting Portland cement mortar containing much less $\mathrm{C}_{3} \mathrm{~A}$, and the mortar suffered from a slighter attack attributed to ettringite formation. Other mineral compositions in SRC are similar to OPC, so the SRC mortar also suffered from the formation of gypsum and thaumasite and it showed limitedly better resistance to sulfate attack at low temperature than the OPC mortar. The main minerals of sulphoaluminate cement are $\mathrm{C}_{4} \mathrm{~A}_{3} \stackrel{\mathrm{S}}{\mathrm{S}}, \mathrm{C}_{2} \mathrm{~S}$, and $\mathrm{C}_{12} \mathrm{~A}_{7}$, and their hydration products mainly contain ettringite, $\mathrm{CSH}$ gel, and $\mathrm{Al}(\mathrm{OH})_{3}$ [15]. Very strong 


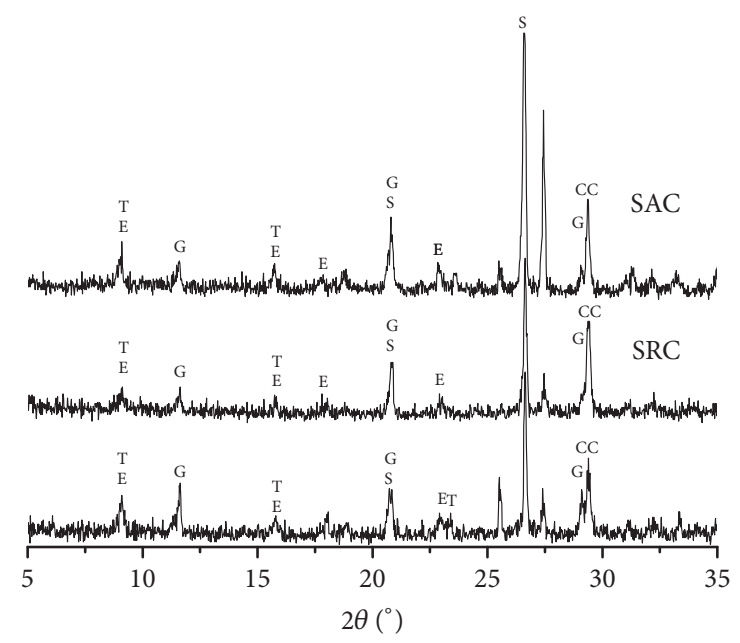

FIGURE 5: XRD patterns of mortars after 1-year immersion in sulfate solution. S: quartz; CC: calcite; E: ettringite; T: thaumasite; G: gypsum.

peaks corresponding to ettringite and weak peaks attributed to portlandite can be found in the XRD pattern of the SAC mortar. On the one hand, there is no enough portlandite or unstable aluminates such as monocarboaluminate or monosulfoaluminate to form gypsum and ettringite. On the other hand, there is less CSH gel for thaumasite sulfate attack in the SAC paste than in the OPC paste. Therefore, the SAC mortar behaves much better than the OPC mortar.

Figure 5 presents the XRD patterns of samples selected from the surfaces of mortars with different types of cement after 1-year immersion. In all samples, even no detectable trace of portlandite can be seen. And a great deal of sulfate-bearing substances including ettringite/thaumasite and gypsum formed in the samples. According to the relative intensities of major peaks at around $9.1^{\circ}$ and $11.6^{\circ} 2 \theta$, there are more sulfate-bearing substances formed in OPC mortar than in SRC and SAC mortars which suffered from slighter deterioration.

It is difficult to distinguish ettringite and thaumasite from XRD patterns when only small amounts are present in a sample being attributed to their very similar crystal structures [16]. So, spectra of samples were further analyzed by FTIR spectra as shown in Figure 6. For all the samples, there are strong peaks at around $1110 \mathrm{~cm}^{-1}$ corresponding to S-O, showing a large number of sulfate-bearing substances [17]. And the OPC mortar shows a stronger peak, attributed to more sulfate-bearing substances, than the other two samples. The C-O peaks at $875 \mathrm{~cm}^{-1}$ and around $1400 \mathrm{~cm}^{-1}$ are occurring in all the samples as expected, and they are attributable to the presence of carbonates. The obvious peaks at $499 \mathrm{~cm}^{-1}$ and $669 \mathrm{~cm}^{-1}$, being assigned to the presence of $\mathrm{SiO}_{6}$ bonds [18], indicate a mass of thaumasite or thaumasitecontaining solid solution formed in the OPC mortar. Weak peaks of $\mathrm{SiO}_{6}$ bonds in the other two samples and the XRD patterns mentioned above show that SRC and SAC postpone the thaumasite formation.

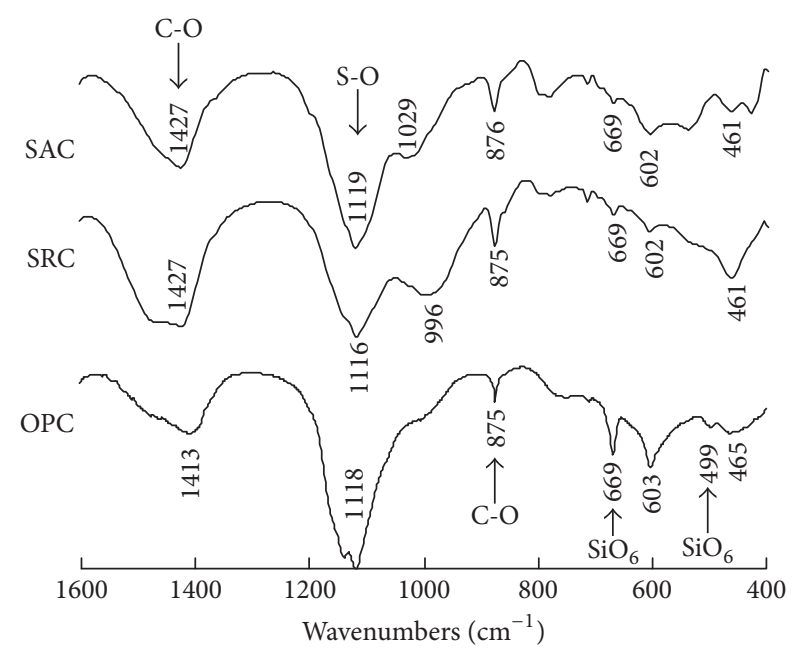

FIGURE 6: FTIR spectra of mortars with different types of cement after 1-year exposure to sulfate solution.

\section{Conclusions}

(i) Based on the mechanical performance degradation, the relative resistance to the thaumasite form of sulfate attack of cement is outlined below, from the best to the worst: mixture of sulphoaluminate cement and OPC, sulphoaluminate cement, sulfate resisting Portland cement, and OPC.

(ii) A lower water-to-cement ratio leads to better resistance to the thaumasite form of sulfate attack of cement mortar.

(iii) After 1 year of exposure to sulfate solution, a great deal of thaumasite or thaumasite-containing materials formed in the OPC mortar, and a trace of thaumasite can also be detected in SRC and SAC mortars. Therefore, the thaumasite form of sulfate attack can be alleviated but cannot be avoided by the use of SAC or SRC.

\section{Conflicts of Interest}

The authors declare that they have no conflicts of interest.

\section{References}

[1] H. F. Sun, B. Hohl, Y. Z. Cao et al., "Jet mill grinding of portland cement, limestone, and fly ash: impact on particle size, hydration rate, and strength," Cement and Concrete Composites, vol. 44, pp. 41-49, 2013.

[2] M. Valcuende, E. Marco, C. Parra, and P. Serna, "Influence of limestone filler and viscosity-modifying admixture on the shrinkage of self-compacting concrete," Cement and Concrete Research, vol. 42, no. 4, pp. 583-592, 2012.

[3] S. Tsivilis, J. Tsantilas, G. Kakali, E. Chaniotakis, and A. Sakellariou, "The permeability of Portland limestone cement concrete," Cement and Concrete Research, vol. 33, no. 9, pp. 1465-1471, 2003. 
[4] S. Tsivilis, E. Chaniotakis, E. Badogiannis, G. Pahoulas, and A. Ilias, "A study on the parameters affecting the properties of Portland limestone cements," Cement and Concrete Composites, vol. 21, no. 2, pp. 107-116, 1999.

[5] N. Saca and M. Georgescu, "Behaviour of Portland limestone cement mortars in magnesium sulfate solution," Romanian Journal of Materials, vol. 44, no. 1, pp. 5-16, 2014.

[6] A. P. Barker and D. W. Hobbs, "Performance of Portland limestone cements in mortar prisms immersed in sulfate solutions at $5^{\circ} \mathrm{C}$, Cement and Concrete Composites, vol. 21, no. 2, pp. 129137, 1999.

[7] A. Skaropoulou, G. Kakali, and S. Tsivilis, "Thaumasite form of sulfate attack in limestone cement concrete: the effect of cement composition, sand type and exposure temperature," Construction and Building Materials, vol. 36, pp. 527-533, 2012.

[8] D. W. Hobbs and M. G. Taylor, "Nature of the thaumasite sulfate attack mechanism in field concrete," Cement and Concrete Research, vol. 30, no. 4, pp. 529-533, 2000.

[9] P. Brown and R. D. Hooton, "Ettringite and thaumasite formation in laboratory concretes prepared using sulfate-resisting cements," Cement and Concrete Composites, vol. 24, no. 3-4, pp. 361-370, 2002.

[10] L. Pelletier-Chaignat, F. Winnefeld, B. Lothenbach, and C. J. Müller, "Beneficial use of limestone filler with calcium sulphoaluminate cement," Construction and Building Materials, vol. 26, no. 1, pp. 619-627, 2012.

[11] J. Zhao, G. Cai, D. Gao, and S. Zhao, "Influences of freeze-thaw cycle and curing time on chloride ion penetration resistance of Sulphoaluminate cement concrete," Construction and Building Materials, vol. 53, pp. 305-311, 2014.

[12] H. Wang, X. Gao, and R. Wang, "The influence of rheological parameters of cement paste on the dispersion of carbon nanofibers and self-sensing performance," Construction and Building Materials, vol. 134, pp. 673-683, 2017.

[13] M. E. Gaze and N. J. Crammond, "Formation of thaumasite in a cement:lime:sand mortar exposed to cold magnesium and potassium sulfate solutions," Cement and Concrete Composites, vol. 22, no. 3, pp. 209-222, 2000.

[14] G. Qu and A. Zhang, "Influence of temperature on the resistance to sulfate attack of limestone filler concrete," Romanian Journal of Materials, vol. 42, no. 4, pp. 381-386, 2012.

[15] X. Fu, C. Yang, Z. Liu, W. Tao, W. Hou, and X. Wu, "Studies on effects of activators on properties and mechanism of hydration of sulphoaluminate cement," Cement and Concrete Research, vol. 33, no. 3, pp. 317-324, 2003.

[16] S. M. Torres, J. H. Sharp, R. N. Swamy, C. J. Lynsdale, and S. A. Huntley, "Long term durability of Portland-limestone cement mortars exposed to magnesium sulfate attack," Cement and Concrete Composites, vol. 25, no. 8, pp. 947-954, 2003.

[17] X. Gao, B. Ma, Y. Yang, and A. Su, "Sulfate attack of cementbased material with limestone filler exposed to different environments," Journal of Materials Engineering and Performance, vol. 17, no. 4, pp. 543-549, 2008.

[18] J. Bensted and S. P. Varma, "Studies of thaumasite-part II," Silictes Industrials, vol. 39, no. 1, pp. 11-19, 1974. 

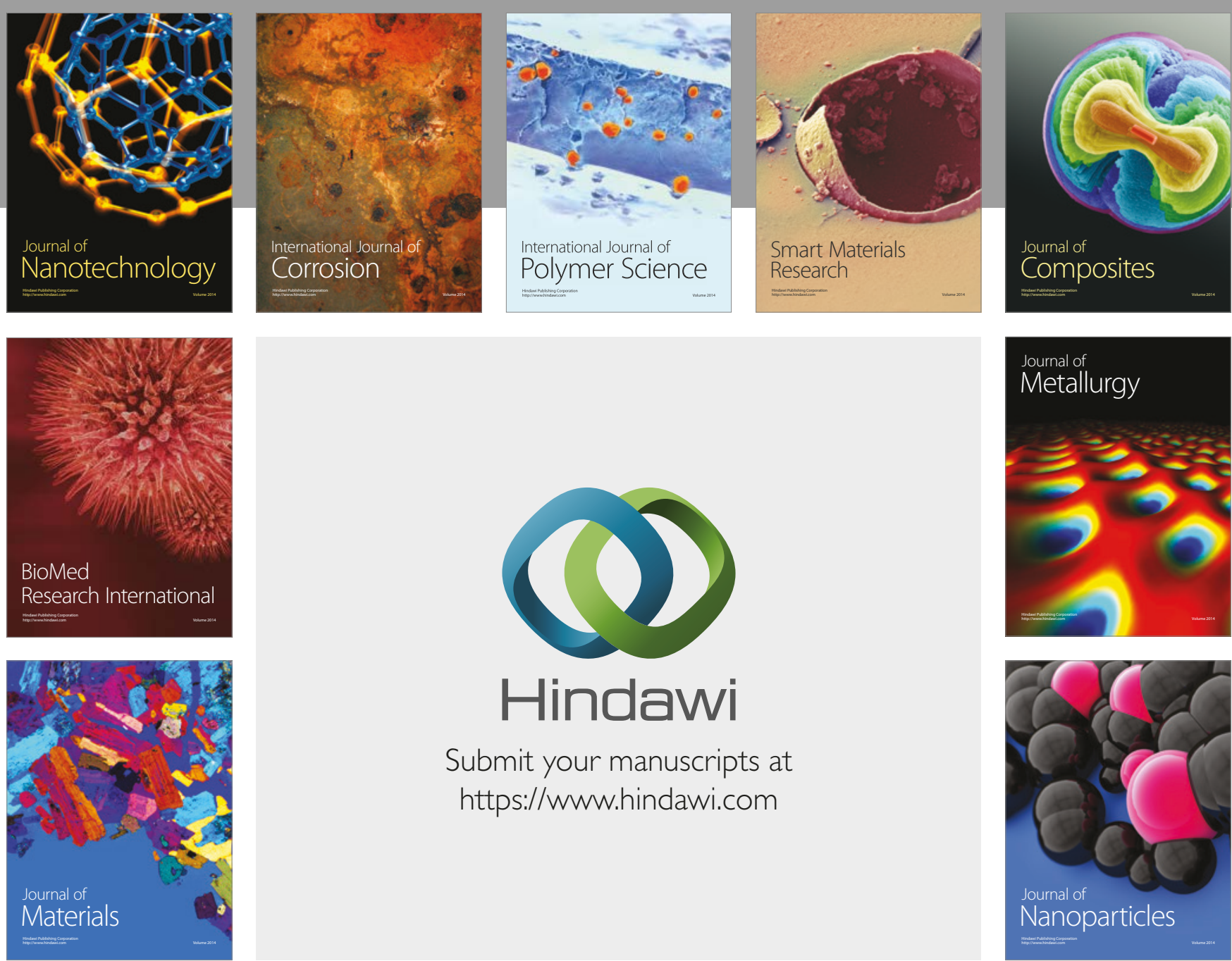

\section{Hindawi}

Submit your manuscripts at

https://www.hindawi.com
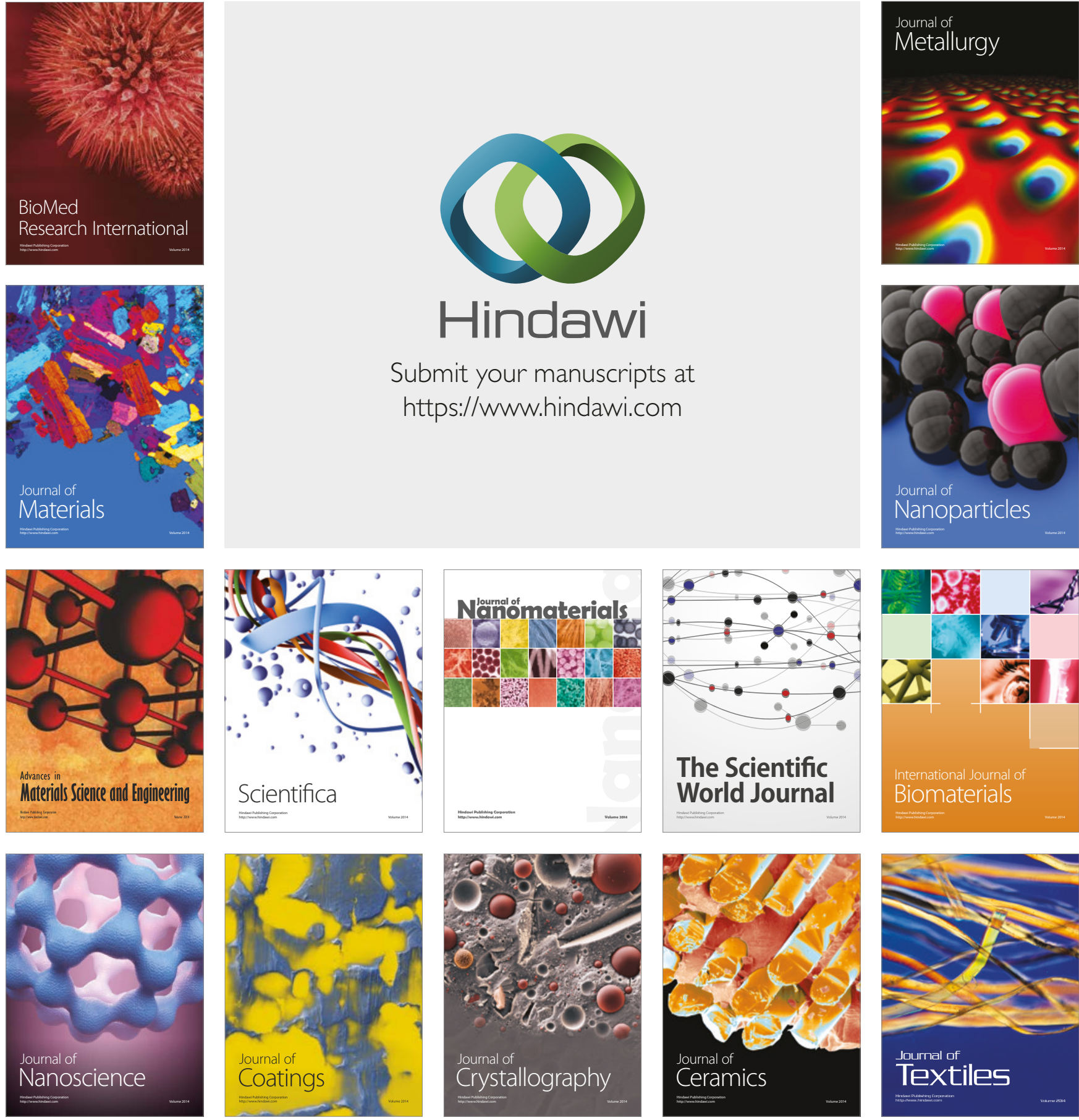

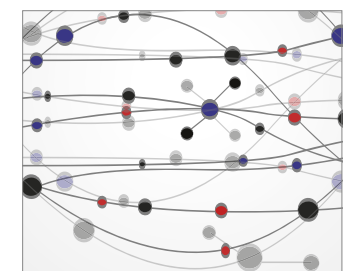

The Scientific World Journal
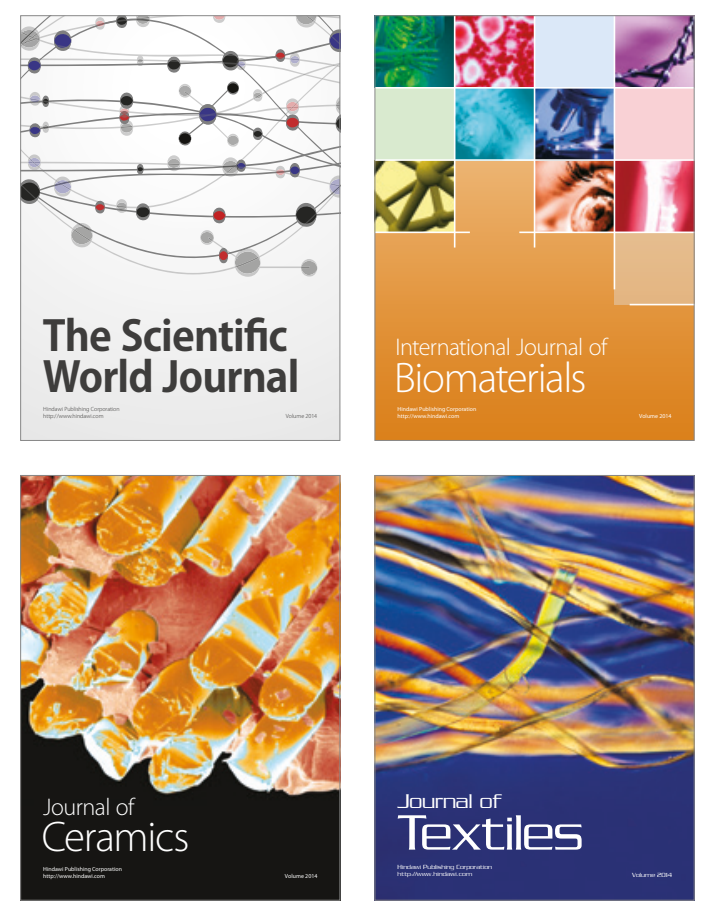